\title{
A TECHNIQUE FOR DIFFERENTIATING ANNUAL RINGS IN INCREMENT CORES FROM DIFFUSE POROUS WOODS ${ }^{1}$
}

\section{By A. H. ROSE -}

INTRODUCTION

Workers in forestry are often called upon to study radial growth from cores taken with an increment borer. The annual rings of conifers are readily distinguishable to the naked eye and can be measured or counted with little or no preparation of the core using a low-powcr microscope. However, this
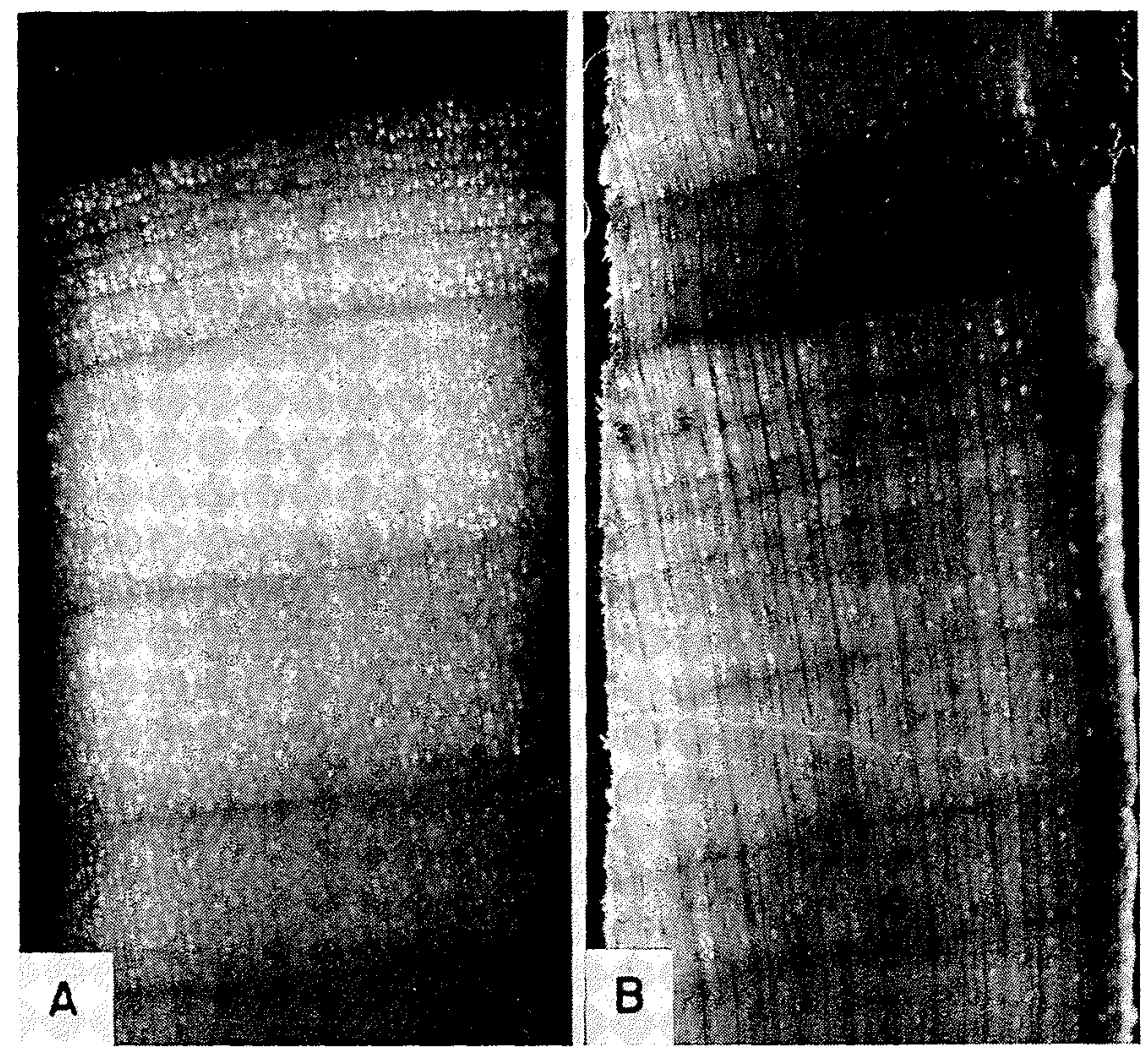

FIGURE 1

Cores of trembling aspen (A) and white birch (B) filled with a light oil and photographed by means of transmitted light using a low-power microscope, (x13). (Photographed by D. C. Anderson).

${ }^{1}$ Contriburion No. 321, Forest Biology Division, Science Service, Department of Agriculture, Otcawa, Canada. Received for publication July 12, 1 y56.

${ }^{2}$ Forest Insect Laboratory, Sault Ste. Maric, Ontario. 
does not apply to cores from diffuse porous woods such as trembling aspen and white birch in which the narrow rings are difficult to distinguish even when the cores have been shaved and moistened or stained, and it is usually necessary to make thin sections to establish the width of the ring with certainty. Marts' method (1), using fluorescent microscopy, gives excellent results but it, too, requires careful preparation of the wood surface.

During a recent study of suppressed radial growth in trembling aspen caused by forest tent caterpillar defoliation, a new technique was developed that requires little core preparation and allows clear differentiation of even the narrowest rings. The cores are made translucent by replacing the air in the wood with a light oil. They are examined, while immersed in oil, with a low-power microscope using transmitted light.

The air spaces can be filled with oil by simple immersion of the cores for a week or more, but better results are obtained by forcing the oil into the spaces under vacuum; 15 inches of vacuum has suitably treated day-old cores in less than a minute. It was also found that a pressure cooker or other air-tight vessel can be substituted for a regular vacuum chamber by placing the container of immersed cores in the vessel, adding some boiling water, and sealing the vessel. As the vessel cools, sufficient vacuum is created to replace the air in the cores with oil. Of various light oils tried, Mechanics Penetrating Oil (Canadian Industries Limited) was found to be the most suitable because its light weight allows fast penetration and its pale color heightens the contrast between spring and summer wood.

Figure 1 illustrates the ring differentiation that can be obtained by this technique in trembling aspen and white birch cores. There was no preparation of the cores other than treatment with oil. Even the very narrow rings (the narrowest ring in each core is about $0.165 \mathrm{~mm}$. wide) are clearly visible.

The main advantage of this technique is that several cores may be treated at one time, resulting in a considerable saving in labor when a large number of cores must be examined. The technique works equally well with green or dry cores and provides clear differentiation of the annual rings even in portions of the core where growth is severely suppressed. No difference in width has been observed in the same ring in fresh cores before and after treatment.

REFERENCE

MARTS, R. O. 1950. Application of fluorescence microscopy and photomicrography to wood tissues. Stain Tech. 25(1):41-44. 